\title{
Increased soluble CD14 in bronchoalveolar lavage fluid of stable lung transplant recipients
}

\author{
C. Ward*, E.H. Walters", L. Zheng", H. Whitford", T.J. Williams", G.I. Snell
}

Increased soluble CD14 in bronchoalveolar lavage fluid of stable lung transplant recipients. C. Ward, E.H. Walters, L. Zheng, H. Whitford, T.J. Williams, G.I. Snell. (C) ERS Journals Ltd 2002.

ABSTRACT: Macrophages, neutrophils and infection have been implicated in the genesis of the bronchiolitis obliterans syndrome (BOS) post lung transplantation. sCD14 is a soluble form of a shed-cell surface protein. It is capable of promoting cytokine-induced inflammation and it's presence in clinically stable lung transplant recipients (LTR) might be important as an early marker of BOS.

Bronchalveolar lavage (BAL) and blood samples were taken from 26 stable LTR, at or near their best forced expiratory volume in one second who were free from infection. sCD14 levels were measured via enzyme-linked immunosorbent assay. Cell counts were performed on unfiltered BAL.

LTR neutrophil count, BAL sCD14 and serum sCD14 levels were higher than controls (median $3.8 \%$ versus $1.3 \%, p<0.05 ; 11.5 \mathrm{ng} \cdot \mathrm{mL}^{-1}$ versus $6 \mathrm{ng} \cdot \mathrm{mL}^{-1}, \mathrm{p}<0.001$; $6.2 \mu \mathrm{g} \cdot \mathrm{mL}^{-1}$ versus $2.4 \mu \mathrm{g} \cdot \mathrm{mL}^{-1}, \mathrm{p}<0.05$, respectively). BAL albumin and $\mathrm{sCD} 14$ correlated (regression coefficient: $0.77, \mathbf{p}<0.001$ ).

In this hypothesis-generating, cross-sectional study, the authors have described for the first time soluble CD14 levels in the bronchoalveolar lavage and serum of stable lung transplant recipients, and show that these are elevated compared to controls. This is a practicable candidate marker system, which can be tested for a predictive role in bronchiolitis obliterans syndrome following lung transplantation. The origin of this cellular protein and its temporal relationship to the development of the bronchiolitis obliterans syndrome remains to be elucidated in more definitive longitudinal studies, which should include other measurements potentially relevant to the innate immune system, such as bronchoalveolar lavage endotoxin levels.

Eur Respir J 2002; 19: 472-478.
*William Leech Centre, Freeman Road Hospital, University of Newcastle upon Tyne, UK. "Dept of Medicine, University of Tasmania, Tasmania and Respiratory Medicine, Alfred Hospital and Monash University Medical School, Melbourne, Australia.

Correspondence: G. Snell, Dept of Respiratory Medicine, Alfred Hospital, Prahran, Melbourne, 3181, Australia. Fax: 61392763434

E-mail: g.snell@alfred.org.au

Keywords: Bronchoalveolar lavage CD14

lung transplantation

Received: March 152001

Accepted after revision October 10 2001

This study was supported by the Alfred Hospital Foundation, the Alfred Whole Time Medical Specialists, National Health and Medical Research Council of Australia and a grant in aid from Novartis.
Chronic rejection, in the form of the bronchiolitis obliterans syndrome (BOS), remains the major obstacle to long-term survival following lung transplantation [1]. The prevalence is estimated to be of the order of $50 \%$ at 3 yrs post-transplant, with a $3-y r 50 \%$ mortality rate after BOS onset [2]. A number of risk factors for the development of the BOS have been defined, including early reperfusion injury, episodes of acute allograft rejection and viral infection [2-4]. Exactly how these factors induce irreversible changes in the airways of lung transplant recipients (LTR) is not known. It has been suggested that the initial insult stimulates increased epithelial and dendritic cell major histocompatability complex expression, which allows enhanced presentation of donor antigens and the subsequent activation of lymphocytes [5]. In turn, this would lead to the recruitment of macrophages, monocytes and neutrophils with the induction of fibrosis via fibrogenic cytokines and growth factors such as tumour necrosis factor (TNF)- $\alpha$ and transforming growth factor-beta [6-8]. Currently, no marker has been shown to predict reliably the development of BOS.

It seems probable that even apparently stable, healthy LTR have a degree of background airway inflammation and may be primed for the development of BOS. In a previous publication, the authors demonstrated that endobronchial biopsies in stable, clinically noninfected LTR have increased CD8 and human leukocyte antigen (HLA) D-related positive cells compared with normal controls [9]. Consistent with this observation, Rizzo et al. [10] noted bronchoalveolar lavage (BAL) HLA class-I antigen levels were elevated in stable LTR compared to a normal population. The levels were higher in those with infection, and even higher again in those with acute rejection. Ross et al. [11] have noted also that isolated transbronchial biopsy evidence of bronchitis or bronchiolitis was associated with long-term refractory airflow obstruction, even where an infective aetiology for the airway inflammation was implicated. The relevance of studies of early pathological changes in clinically-well LTR is worth emphasizing, since this would seem a logical point for intervention, if such changes could be shown to predate the onset of BOS.

CD14 is a surface protein found on macrophages and activated neutrophils and serves as the cellular receptor for lipopolysaccharide (LPS), which is a 
major component of the outer membrane of Gramnegative bacteria [12]. CD14 can indirectly trigger the release of interleukin-1, $-6,-8$ and TNF- $\alpha$ [13]. CD14dependant mechanisms of inflammation have been shown in acute respiratory distress syndrome (ARDS) [14], sarcoidosis [15] and asthma [16]. The soluble form of CD14 (sCD14) is generated by proteolytic shedding of the membrane-associated form (mCD14) during cellular activation and can be detected proportionately in the BAL $[15,17]$. In its own right, sCD14 appears to interact with LPS, further amplifying cellular responses [17]. It is not clear if BAL sCD14 originates locally or represents leakage from the peripheral blood. In the lung transplant setting, even in clinically-stable LTR, airway inflammation commonly occurs as a result of both allogeneic immune system activation and coexistent infection or microbial colonization. A study of the BAL and serum expression of the CD14 cell surface marker is therefore relevant.

The BAL albumin level has been used as a surrogate marker of alveolar-capillary membrane dysfunction. In a radioisotope study of patients with interstitial lung disease, the authors have suggested that BAL albumin levels were related to the effects of lung inflammation rather than acute flux from the serum [18]. A similar logic may apply in a study of LTR.

There is no description of the sCD14 system in stable LTR. The authors, therefore, have tested the hypotheses that sCD14 is elevated in the BAL and peripheral blood of clinically stable LTR, free from evidence of allograft rejection or infection, and that elevated BAL sCD14 relates to increased levels in the lung compartment, rather than representing microvascular leakage and a surrogate of blood levels.

\section{Methods}

The study was approved by the Alfred Hospital Ethics Review Committee, and patients gave their informed consent. BAL and peripheral blood samples were taken from 26 stable, nonsmoking LTR at routine follow-up, 58-1,301 days post-transplant (median 195 days). Patients were excluded if they had clinical or bronchoscopic evidence of intercurrent lung infection or acute or chronic lung rejection. In particular, patients with clinical or bronchoscopic bronchitis were excluded, i.e. those with cough, sputum or excessive or purulent bronchoscopic secretions. At the time of the study all had forced expiratory volume in one second (FEV1) measurements at, or near, their maximum post-transplant values (median 100\%, range: $84-100 \%$ ). Clinical details are presented in table 1 .

Nineteen asymptomatic nonsmoking volunteers

Table 1. - Clinical details of stable transplant recipients

\begin{tabular}{|c|c|c|c|c|c|c|c|c|c|}
\hline Sex & $\begin{array}{l}\text { Age } \\
\text { yrs }\end{array}$ & $\begin{array}{l}\text { Original } \\
\text { disease }\end{array}$ & $\begin{array}{l}\text { Days post- } \\
\text { transplant }\end{array}$ & $\begin{array}{l}\text { Maximum } \\
\text { FEV1 \% }\end{array}$ & $\begin{array}{l}\text { Rejection } \\
\text { grade }\end{array}$ & $\begin{array}{l}\text { BAL micro- } \\
\text { organisms }\end{array}$ & $\begin{array}{l}\text { CsA level } \\
\mu \mathrm{g} \cdot \mathrm{L}^{-1}\end{array}$ & $\begin{array}{l}\text { Pred dose } \\
\text { mg }\end{array}$ & $\begin{array}{c}\text { Aza dose } \\
\text { mg }\end{array}$ \\
\hline M & 34 & $\mathrm{BR}$ & 376 & 84 & $\mathrm{~A} 1 \mathrm{~B} 0$ & nil & 162 & 15 & 25 \\
\hline $\mathrm{F}$ & 32 & $\mathrm{CF}$ & 67 & 95 & A0B 0 & nil & 360 & 15 & 75 \\
\hline $\mathrm{F}$ & 23 & $\mathrm{CF}$ & 102 & 100 & $\mathrm{~A} 0 \mathrm{~B} 0$ & nil & 257 & 15 & 25 \\
\hline $\mathrm{F}$ & 41 & PPH & 200 & 100 & A1B2 & $\mathrm{CMV}, \mathrm{SA}$ & 195 & 15 & 125 \\
\hline M & 36 & $\mathrm{CF}$ & 75 & 100 & A1B2 & PsA, ASP & 820 & 20 & 75 \\
\hline $\mathrm{F}$ & 34 & $\mathrm{E}$ & 190 & 100 & $\mathrm{~A} 0 \mathrm{~B} 0$ & CMV & 264 & 15 & 75 \\
\hline $\mathrm{F}$ & 35 & E & 419 & 100 & A0B0 & nil & 210 & 12.5 & 75 \\
\hline $\mathrm{F}$ & 42 & E & 542 & 100 & A1BX & nil & 134 & 7.5 & 50 \\
\hline M & 22 & CF & 186 & 100 & A1BX & CMV & 432 & 7.5 & 50 \\
\hline $\mathrm{F}$ & 31 & $\mathrm{CF}$ & 58 & 100 & A1B2 & CMV & 710 & 20 & 50 \\
\hline M & 33 & $\mathrm{E}$ & 1301 & 100 & $\mathrm{~A} 0 \mathrm{~B} 0$ & SPn & 265 & 7.5 & 100 \\
\hline M & 46 & $\mathrm{~S}$ & 146 & 100 & A0B2 & CMV & 311 & 17.5 & 25 \\
\hline $\mathrm{F}$ & 46 & $\mathrm{BR}$ & 107 & 100 & A1BX & SA & 307 & 15 & 50 \\
\hline $\mathrm{F}$ & 40 & $\mathrm{BR}$ & 189 & 100 & A1B0 & nil & 225 & 12.5 & 50 \\
\hline M & 20 & $\mathrm{E}$ & 732 & 99 & $\mathrm{~A} 0 \mathrm{~B} 0$ & nil & 243 & 7.5 & 100 \\
\hline M & 39 & $\mathrm{CF}$ & 547 & 91 & A1B0 & PsA, CMV & 493 & 7.5 & 50 \\
\hline $\mathrm{F}$ & 35 & PPH & 376 & 92 & $\mathrm{~A} 0 \mathrm{~B} 0$ & nil & 379 & 7.5 & 100 \\
\hline M & 54 & Em & 545 & 99 & A1B1 & SMalt & 276 & 15 & 50 \\
\hline $\mathrm{F}$ & 58 & $\mathrm{BR}$ & 189 & 100 & $\mathrm{~A} 0 \mathrm{~B} 0$ & CMV & 169 & 15 & 50 \\
\hline M & 53 & Em & 91 & 100 & A0BX & CMV & 405 & 17.5 & 25 \\
\hline M & 47 & EA & 81 & 92 & A1BX & SA & 373 & 20 & 0 \\
\hline $\mathrm{F}$ & 22 & $\mathrm{CF}$ & 357 & 98 & $\mathrm{~A} 1 \mathrm{~B} 2$ & PsA, SA & 107 & 7.5 & 25 \\
\hline M & 58 & Em & 173 & 100 & $\mathrm{~A} 0 \mathrm{~B} 0$ & nil & 227 & 15 & 50 \\
\hline $\mathrm{F}$ & 21 & $\mathrm{CF}$ & 294 & 95 & A1B2 & SA & 405 & 15 & 0 \\
\hline $\mathrm{F}$ & 58 & BR & 200 & 94 & A0BX & PsA & 208 & 15 & 100 \\
\hline $\mathrm{F}$ & 29 & $\mathrm{E}$ & 283 & 100 & A0B0 & nil & 492 & 15 & 50 \\
\hline & $36(20-58)$ & & $195(58-1301)$ & $100(84-100)$ & & & $270.5(134-82)$ & $15(7.5-20)$ & $50(0-125)$ \\
\hline
\end{tabular}

FEV1: forced expiratory volume in one second; M: male; F: female; BR: bronchiectasis; CF: cystic fibrosis; PPH: primary pulmonary hypertension; E: Eisenmengers syndrome; S: sarcoid; Em: emphysema; EA: extrinsic alveolitis; CMV: cytomegalovirus (viral IF); SA: Staphylococcus aureus; PsA: Pseudomonas aeruginosa; ASP: aspergillus; SPn: Streptococcus pneumoniae; SMalt: Stenotrophomonas maltophilia; CsA: cyclosporine; Pred: prednisolone; Aza: azathioprine; A: acute rejection 0-4; B: airway inflammation 0-4 (X=ungradable). 
were recruited as controls. This group had a mean age of 25 yrs (range: 18-38 yrs). They were nonasthmatic, with a negative methacholine challenge. Selection and procurement of the pulmonary donor was in accordance with guidelines described elsewhere $[1,19]$. No organs came from donors with known respiratory disease or evidence of airflow obstruction.

\section{Immunosuppression}

All patients began standardized triple therapy immediately after operation. Maintenance therapy included cyclosporine (to achieve a blood level of 200-350 $\mu \mathrm{g} \cdot \mathrm{L}^{-1} \quad$ (enzyme-multiplied immunoassay technique (EMIT) assay, parent drug only; Syva, CA, USA), azathioprine $\left(1.0-2.0 \mathrm{mg} \cdot \mathrm{kg}^{-1} \cdot \mathrm{day}^{-1}\right)$ and prednisolone $\left(0.15-0.25 \mathrm{mg} \cdot \mathrm{kg}^{-1} \cdot \mathrm{day}^{-1}\right)[1,19]$.

\section{Lung function testing}

Lung function testing was undertaken immediately prior to the bronchoscopy. Spirometry was performed routinely via a Masterscreen Spirometer (Jaeger, Wurzburg, Germany) twice-weekly up to 6 months post-transplant and monthly beyond this time. The study FEV1 was compared to the recipient's previous best value post-transplant.

\section{Fibreoptic bronchoscopy}

Fibreoptic bronchoscopy was performed under intravenous sedation with midazalam (Roche, France). The airways were anaesthetised with topical $1.5 \%$ lidocaine and a $3 \times 60 \mathrm{~mL}$ BAL of middle lobe or lingula was carried out after wedging the bronchoscope in a suitable subsegment. The fluid was immediately aspirated into a glass container at a negative pressure of $-10.64 \mathrm{kPa}(-80 \mathrm{mmHg})$ and transported to the laboratory at $4{ }^{\circ} \mathrm{C}$. This was followed by transbronchial biopsies (TBB) of distal tissue.

\section{Bronchoalveolar lavage cell processing}

Cell counts were performed on the unfiltered BAL fluid using a modified Neubauer haemocytometer (Weber Scientific, Middlesex, UK). Duplicate cytocentrifuge preparations were made using $200 \mu \mathrm{L}$ of unfiltered BAL aspirate (Shandon Cytospin III; Shandon, Runcorn, Cheshire, UK) $82 \times g$ for $10 \mathrm{~min}$ ), and stained with Diff-Quick (Scientific Products Co., McGaw Park, USA). Cell counts were performed by counting 500 cells $\cdot$ slide ${ }^{-1}$ to obtain a mean, and reported as percentages.

\section{Bronchoalveolar lavage soluble CD14 and albumin levels}

BAL sCD14 and albumin levels were measured in the unconcentrated BAL supernatant. sCD14 was measured by a commercially available, sandwich enzyme-linked immunosorbent assay (ELISA) kit (Immunobiological Laboratories, Hamburg, Germany). Albumin was measured via immunonephelometry (Beckman Instruments, Fullerton, USA). The intraassay coefficient of variation (c.v.) for the sCD14 assay was $6 \%$, with an intra-assay c.v. of $8 \%$.

\section{Bronchoalveolar lavage microbiological assessment}

BAL microbiological assessment was undertaken on a portion of the supernatant. Standard microscopy and culture for bacteria (including mycobacteria), fungi and respiratory viruses were performed in all LTR. Shell-vial culture, with detection of cytomegalovirus-infected cells by immunofluoresence, was also performed routinely.

\section{Transbronchial biopsies}

In each LTR, five to seven TBB were taken using alligator forceps. Using haematoxylin and eosin tissue staining, an experienced histopathologist reported the presence of acute or chronic rejection according to standard criteria [20].

\section{Venepuncture and blood sampling}

Venepuncture and blood sampling were performed immediately prior to bronchoscopy. Cyclosporine-A serum levels were measured using the EMIT assay referred to earlier. In a subgroup of 12 LTR and 10 controls, sCD14 was measured in serum using ELISA and albumin was measured in serum using the Bromocresol Purple method (Randox Laboratories, Ardmore, UK).

\section{Statistical analysis}

Variables were not normally distributed and were compared using the nonparametric, two-tailed MannWhitney U-test, and medians and ranges are quoted. Correlation coefficients (r) were obtained by Spearman's rank method. p-Values $<0.05$ were considered statistically significant.

\section{Results}

The clinical details of the study population at the time of the bronchoscopy are shown in table 1 . The median cyclosporine serum level was $271 \mu \mathrm{g} \cdot \mathrm{L}^{-1}$ (range: $134-820 \mu \mathrm{g} \cdot \mathrm{L}^{-1}$ ), median prednisolone dose was $15 \mathrm{mg}$ daily $(7.5-20 \mathrm{mg})$, and the median azathioprine dose was $50 \mathrm{mg}$ daily $(0-125 \mathrm{mg})$.

\section{Bronchoalveolar lavage}

The BAL return was significantly less in the LTR group compared to controls (median $89 \mathrm{~mL}$ (range: $40-112, \mathrm{n}=26)$ versus $120 \mathrm{~mL}(80-145, \mathrm{n}=9), \mathrm{p}<0.01$; table 2). Neutrophil counts were significantly elevated 
Table 2. - Bronchoalveolar lavage parameters in lung transplant recipients versus control subjects

\begin{tabular}{|c|c|c|c|c|c|c|c|c|}
\hline & $\begin{array}{l}\text { Subjects } \\
\text { n }\end{array}$ & $\begin{array}{l}\text { Volume } \\
\mathrm{mL}\end{array}$ & $\begin{array}{l}\text { Total cell count } \\
\left(\text { cells } \times 1000 \cdot \mathrm{mL}^{-1}\right)\end{array}$ & $\underset{\%}{\operatorname{Lymphs}}$ & $\underset{\%}{\mathrm{AM}}$ & $\underset{\%}{\mathrm{PMN}}$ & $\begin{array}{c}\mathrm{sCD} 14 \\
\mathrm{ng} \cdot \mathrm{mL}^{-1}\end{array}$ & $\begin{array}{l}\text { Albumin } \\
\mu \mathrm{g} \cdot \mathrm{mL}^{-1}\end{array}$ \\
\hline LTR & 26 & & & & & & & \\
\hline Median & & $89^{* *}$ & 175 & 17.8 & 72.2 & $3.8^{*}$ & $11.5^{* * *}$ & $39^{*}$ \\
\hline Range & & $40-112$ & $100-171$ & $2.5-78$ & $20-92$ & $0.4-39$ & $3-100$ & $15-324$ \\
\hline Normal controls & 9 & & & & & & & \\
\hline Median & & 120 & 150 & 13.1 & 73.9 & 1.3 & 6.0 & 26 \\
\hline Range & & 80-145 & $93-270$ & $4.8-35$ & $61-94$ & $1.1-5.3$ & $1.0-8.0$ & $20-55$ \\
\hline
\end{tabular}

Lymphs: lymphocyte; AM: alveolar macrophage; PMN: neutrophil; sCD14: soluble CD14; LTR: lung transplant recipients. *: $\mathrm{p}<0.05$ versus control; $* *: \mathrm{p}<0.01$ versus control; $* * *: \mathrm{p}<0.001$ versus control.

in the LTR group $(3.8 \%(0.4-39.8, \mathrm{n}=26)$ versus $1.3 \%$ $(1.1-5.3, \mathrm{n}=9) ; \mathrm{p}<0.05)$.

sCD14 was elevated in the LTR group $\left(11.5 \mathrm{ng} \cdot \mathrm{mL}^{-1} \quad\left(5.3-100.0 \mathrm{ng} \cdot \mathrm{mL}^{-1}, \quad \mathrm{n}=25\right) \quad\right.$ versus $6.0 \mathrm{ng} \cdot \mathrm{mL}^{-1}\left(1.0-8.0 \mathrm{ng} \cdot \mathrm{mL}^{-1}, \mathrm{n}=9\right), \mathrm{p}<0.001$; fig. 1$)$. Albumin was increased in the LTR group $\left(39 \mu \mathrm{g} \cdot \mathrm{mL}^{-1}\right.$ $\left(15-324 \mu \mathrm{g} \cdot \mathrm{mL}^{-1}\right)$ versus $26 \mu \mathrm{g} \cdot \mathrm{mL}^{-1}\left(20-55 \mu \mathrm{g} \cdot \mathrm{mL}^{-1}\right)$; $\mathrm{p}<0.05)$. There was a significant correlation between BAL sCD14 and albumin levels, $r=0.77, n=24$, $\mathrm{p}<0.001$ (fig. 2). BAL sCD14 did not significantly correlate with BAL return, or macrophage or lymphocyte or neutrophil percentage.

Microbiological examination demonstrated one fungus, 11 bacteria and eight viruses in 16 recipients (table 1), although all were considered both clinically and microbiologically to be commensals; pneumonitis or bronchitis were not present and no patient had a history of clinical infection or rejection in the prior month. Cytomegalovirus cytopathic effect was not seen on BAL cytological analysis or TBB histology. In this LTR cohort, sCD14 results were not significantly different when analysed according to the presence of bacteria or cultureable viruses in the BAL (table 3).

\section{Serum}

sCD14 in stable LTR group was elevated $\left(6.2 \mu \mathrm{g} \cdot \mathrm{mL}^{-1}\left(1.4-10.0 \mu \mathrm{g} \cdot \mathrm{mL}^{-1}, \mathrm{n}=12\right)\right.$ versus $2.4 \mu \mathrm{g} \cdot \mathrm{mL}^{-1}$ $\left(0-3.4 \mu \mathrm{g} \cdot \mathrm{mL}^{-1}, \mathrm{n}=10\right), \mathrm{p}<0.05$; fig. 3$)$, but there was

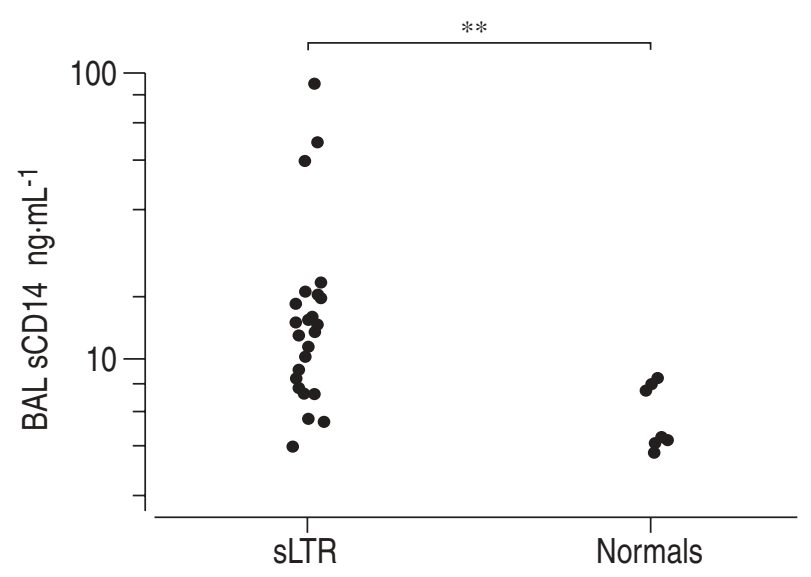

Fig. 1.-A comparison of bronchoalveolar lavage (BAL), soluble CD14 (sCD14) in stable lung transplant recipients (sLTR) and controls. ${ }^{* *}: \mathrm{p}<0.01$. no significant correlation between serum and BAL sCD14 levels.

In the LTR group there was no significant correlation between SCD14 nor albumin levels in BAL or serum, and neither the time post-transplant nor the levels of immunosuppressive therapy. Although no patient had either acute or chronic allograft rejection, there was no significant correlation between sCD14 or albumin levels and the residual "a" or "b" International Society for Heart and Lung Transplantation rejection grading (data not shown).

\section{Discussion}

In this hypothesis-generating, cross-sectional study, the authors have described for the first time the levels of sCD14 in BAL and serum in LTR. BAL and serum sCD14 was elevated, even in clinically-stable LTR, free from evidence of clinically-significant infection, when compared to normal controls. BAL albumin levels were raised also and significantly correlated with sCD14 levels. Serum levels of sCD14 did not directly correlate with BAL levels, indicating high lung levels of sCD14, rather than a surrogate marker of blood levels following simple microvascular leakage, during BAL. BAL sCD14 did not correlate with any particular cell population in the BAL, nor with the presence of BAL micro-organisms. The origin of sCD14 and its temporal relationship to the development of

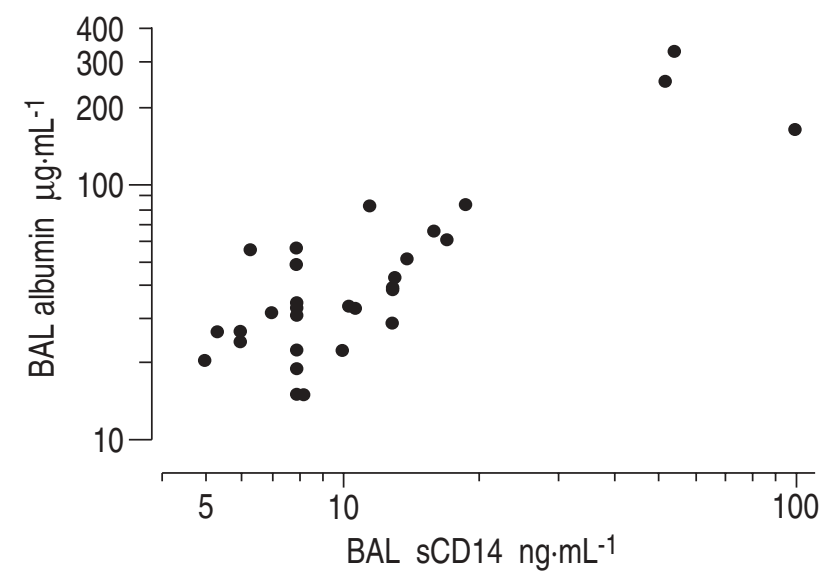

Fig. 2.- The correlation between bronchoalveolar lavage (BAL), soluble CD14 (sCD14) and albumin levels. Regression coefficient $=0.77 ; \mathrm{p}<0.001$. 
Table 3.-Bronchoalveolar lavage parameters in lung transplant recipients with and without organisms in the bronchoalveolar lavage

\begin{tabular}{|c|c|c|c|c|c|c|c|c|}
\hline & Subjects $\mathrm{n}$ & $\begin{array}{l}\text { Volume } \\
\mathrm{ml}\end{array}$ & $\begin{array}{l}\text { Total cell count } \\
\left(\text { cells } \times 1000 \cdot \mathrm{mL}^{-1}\right)\end{array}$ & $\underset{\%}{\operatorname{Lymphs}}$ & $\underset{\%}{\mathrm{AM}}$ & $\underset{\%}{\mathrm{PMN}}$ & $\begin{array}{l}\mathrm{sCD} 14 \\
\mathrm{ng} \cdot \mathrm{mL}^{-1}\end{array}$ & $\begin{array}{l}\text { Albumin } \\
\mu \mathrm{g} \cdot \mathrm{mL}^{-1}\end{array}$ \\
\hline $\begin{array}{l}\text { With only CMV } \\
\text { on culture }\end{array}$ & 6 & & & & & & & \\
\hline Median & & 100 & 180 & 26 & 61 & 5 & 9.8 & 43 \\
\hline Range & & $68-110$ & $100-430$ & $4.8-78$ & $50-89$ & $2.0-40$ & $8.0-100$ & 19-162 \\
\hline $\begin{array}{l}\text { With bacteria } \\
\text { on culture }\end{array}$ & 10 & & & & & & & \\
\hline Median & & 87 & 260 & 12 & 81 & 3.7 & 15 & 48 \\
\hline Range & & $40-109$ & $140-1700$ & $3.8-32$ & $63-90$ & $0.4-10$ & $5.3-54$ & $22-324$ \\
\hline Without organisms & 10 & & & & & & & \\
\hline Median & & 85 & 130 & 17 & 74 & 3.7 & 10.7 & 33 \\
\hline Range & & $59-112$ & $110-440$ & $2.5-32$ & 64-92 & $1.6-18$ & $6.3-16$ & $15-64$ \\
\hline
\end{tabular}

Lymphs: lymphocytes; AM: alveolar macrophage; PMN: neutrophils; sCD14: soluble CD14; CMV: cytomegalovirus.

the BOS remains to be elucidated in more definitive longitudinal studies, which should also include other measurements potentially relevant to the innate immune system, such as BAL endotoxin levels.

Accumulation of sCD14 in the airway may arise from two possible sources: either local secretion by bronchoalveolar and interstitial macrophages or extravasation from the intravascular compartment; these are not mutually exclusive. In favour of local production are experiments showing upregulation of CD14 expression in pulmonary diseases characterized by chronic alveolar macrophage activation [21, 22]. Using radioisotope flux studies in interstitial lung disease, the authors have suggested that elevated BAL albumin levels are related to local inflammation, rather than acute permeability changes due to the BAL procedure itself [18]. In favour of extravasation is the work of DubIN et al. [16], their study showed that apparently maximal rates of $\mathrm{sCD} 14$ release, from antigen-challenged BAL macrophages could only account for $2 \%$ of sCD14 found in BAL. Supporting this view, it is notable that blood monocytes are potent producers of CD14 [17]. The results from this study, which indicated that there was no relationship between BAL and blood sCD14, support the hypothesis that increased BAL sCD14 is due, at least in part, to local production.

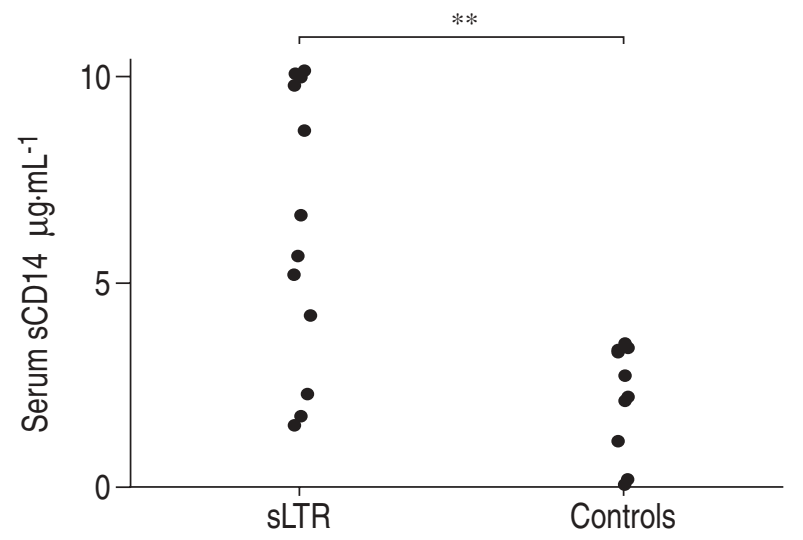

Fig. 3. - A comparison of serum soluble CD14 (sCD14) in stable lung transplant recipients (sLTR) and controls. ${ }^{* *}: \mathrm{p}<0.01$.
Given that there are close relationships between bacterial endotoxin, LPS and CD14, the carriage of micro-organisms in the airways in LTR warrants consideration as a potential cause of elevated BAL sCD14 levels. This has therapeutic implications, since monoclonal antibodies against CD14 have been shown to protect a primate model against endotoxin-induced shock [23]. In this primate experiment, infusion of anti-CD14 antibodies reduced plasma cytokine and BAL protein levels in the face of an endotoxin challenge. Although in the present study the authors chose to have clinically and bronchoscopically "noninfected" patients at entry by standard criteria, careful microbiological assessment did demonstrate organisms in a number of BAL samples. Negative BAL Gram-stains confirmed that these patients were carrying only a low load of organisms. The lack of correlation between the presence of a BAL organism and other BAL results (table 3 ) may be a real finding, although in future studies, quantitative cultures and direct LPS and LPS-binding protein measurements should explore this relationship further. It is a drawback of the present study that such data could not be obtained contemporaneously with the sCD14 levels due to lack of sufficient biological material.

It may well be that subclinical, persistent infection in the airways is not harmless, but is an added cofactor to airway cellular activation and long-term damage. In a recent flow cytometric study, the authors showed that a number of alveolar macrophage surface markers, associated with innate immunity against bacteria, fungi and viruses, were suppressed in both stable LTR and those with BOS, contrasting with increased natural killer and activated CD8 lymphocytes [24]. Considered together, the present sCD14 work and recent flow cytometry data [24], support the emergent hypothesis that even in clinically-stable lung allograft recipients there exists complex lymphocyte and macrophage changes, that may result from clinically-silent infection, partially-suppressed rejection, or both.

Using a similar ELISA measurement system as in the current study, MARTIN et al. [14], found sCD14 elevated in both BAL and serum in patients with 
ARDS, bacterial pneumonia and diffuse interstitial lung diseases. Although the measured levels in both the BAL and blood compartments were comparable to the present study, it seems surprising that stable and otherwise healthy LTR would have values similar to those seen in these extensive lung diseases, including ARDS. However, STRIz et al. [15] demonstrated similar BAL sCD14 levels in inactive sarcoidosis and interstitial lung disease compared to the LTR group in the present study. They showed higher values in the group with clinically active sarcoidosis. DubIN et al. [16] studied BAL sCD14 in both asthmatic and control groups. Levels were generally slightly lower than in the present LTR study and there was no statistical difference between their two groups. Overall, the sCD14 BAL levels are remarkably comparable between all these different studies, including this current work, given that a certain amount of diversity will be inevitable due to the variability of BAL return, dilutional factors and assay systems.

In the current study, BAL returns were higher in the control group and it is possible that relative, epithelial lining fluid, solute concentration contributed to the higher levels of BAL sCD14 and albumin in the LTR group. BAL sCD14 did not correlate with BAL return levels however, and the authors feel that the results were not confounded by BAL return. The latest recommended guidelines for quoting BAL solute concentrations is an amount $\cdot \mathrm{mL}^{-1}$ returned, because the degree of dilution is essentially impossible to precisely define [25].

In ARDS, MARTIN et al. [14] found a strong correlation between sCD14 levels, neutrophils and total protein concentration in BAL. LPS-induced variations in the expression of neutrophil mCD14 have been shown to be an important risk factor in the development of ARDS [26]. In a rabbit model, infusing LPS and complement, results in increased neutrophil accumulation within the lung and increased albumin leakage into alveolar spaces [27]. Interestingly, the present study showed a trend towards a correlation between BAL neutrophils and sCD14 levels, although this did not reach significance. The similarity between patient subgroups in table 3 suggests that airway colonization with organisms does not fully explain the findings of an increase in sCD14 levels.

BAL neutrophilia has been linked with the development of BOS [8], although the neutrophil is not necessarily the cell responsible for effecting airway damage. Other authors have suggested that serum sCD14 levels in septic patients [28], and BAL sCD14 levels in tuberculosis [29] and sarcoidosis [15], reflect monocyte/macrophage activation. The authors have found previously an increase in macrophage and lymphocyte numbers in endobronchial biopsies in stable LTR [9]. In the current study, the authors did not find a relationship between serum or BAL SCD14 and the percentage of BAL macrophages, but a macrophage source cannot be dismissed since it may be the activity of these cells rather than their actual number that is relevant.

In conclusion, it is known that even stable lung transplant recipients have airway mononuclear cell inflammation despite triple immunosuppression [9] and that neutrophilia becomes prominent with the development of bronchiolitis obliterans syndrome [8]. Although this study was not designed to explore the possible relationship between bronchiolitis obliterans syndrome and soluble CD14 levels, it is possible that CD14 is an early and active participant in this process. Airway inflammation in clinically stable lung transplant recipients may go on to the bronchiolitis obliterans syndrome, but the trigger for irreversible structural remodelling and scarring of the airway is poorly understood, hence, studies of stable lung transplant recipients are a logical first step in such programmes of research. A role for airway lipopolysaccharide, related to bacterial colonization or contamination and acting via $\mathrm{CD} 14$, remains to be excluded. The findings presented here, although the first description of soluble CD14 in lung transplantation, are inherently limited by the cross-sectional nature of this study. However, they do indicate that a simple blood and bronchoalveolar lavage assessment of soluble CD14 may represent a logical candidate marker for lung allograft recipients, in future work aimed at predicting those at risk of bronchiolitis obliterans syndrome. More definitive, longitudinal studies are underway to track soluble CD14 levels and its potential relationship to bronchiolitis obliterans syndrome development.

Acknowledgements. The authors would like to thank B. Orsida for technical assistance in bronchoalveolar lavage sample reception. C. Ward is an ERS research fellow.

\section{References}

1. Cooper JD, Patterson GA. Trulock EP and the Washington University Lung Transplant Group. Results of single and bilateral lung transplantation in 131 consecutive recipients. $J$ Thorac Cardiovasc Surg 1994; 107: 460-471.

2. Sharples LD, Tamm RM, McNeil K, Stewart S, Wallwork J. Development of bronchiolitis obliterans syndrome in recipients of heart-lung transplantation early risk factors. Transplantation 1996; 61: 560-566.

3. Azuma H, Tilney N. Chronic graft rejection. Curr Opin Immunol 1994; 6: 770-776.

4. Duncan SR, Paradis IL, Similo SL, et al. Ganciclovir prophylaxis for cytomegalovirus infection in pulmonary allograft recipients. Am Rev Respir Dis 1992; 46: 1213-1215.

5. Paradis I, Youssem SA, Griffith B. Airway obstruction and bronchiolitis obliterans after lung transplantation. Clin Chest Med 1993; 14: 751-763.

6. Shaw RJ. The role of lung macrophages at the interface between chronic inflammation and fibrosis. Respir Med 1991; 85: 267-273.

7. Nickerson P, Steurer W, Steiger J. Cytokines and the Th1/Th2 paradigm in transplantation. Curr Opin Immunol 1994; 6: 757-764.

8. Di Giovine B, Lynch JP, Martinez FJ, et al. Bronchoalveolar lavage neutrophilia is associated with 
obliterative bronchiolitis after lung transplantation. J Immunol 1996; 157: 4194-4202.

9. Snell GI, Ward C, Wilson J, Orsida B, Williams TJ, Walters EH. Immunopathological changes in the airways of stable lung transplant recipients. Thorax 1997; 52: 322-328.

10. Rizzo M, Sundaresan S, Lynch J, et al. Increased concentration of soluble human leukocyte antigen class I levels in the bronchoalveolar lavage of human pulmonary allografts. J Heart Lung Transplant 1997; 16: $1135-1140$

11. Ross DJ, Marchevsky A, Kramer M, Kass RM. "Refractoriness" of airflow obstruction associated with isolated lymphocytic bronchiolitis/bronchitis in pulmonary allografts. J Heart Lung Transplant 1997; 16: 832-838.

12. Wright SD, Ramos RA, Tobias PS, Ulevitch RJ, Mathison JC. CD14 serves as the cellular receptor for complexes of lipopolysaccharide with lipopolysaccharide binding protein. Science 1990; 249: 1431-1433.

13. Dentener MA, Bazil V, von Asmuth VJU, Ceska M, Buurman WA. Involvement of CD14 in lipopolysaccharide induced tumor necrosis factor-alpha, IL-6 and IL-8 release by human monocytes and alveolar macrophages. J Immunol 1993; 150: 2885-2991.

14. Martin TR, Rubenfeld GD, Ruzinski JT, et al. Relationship between soluble CD14, lipopolysaccharide binding protein, and the alveolar inflammatory response in patients with Acute Respiratory Distress Syndrome. Am J Respir Crit Care Med 1997; 155: $937-$ 944.

15. Striz I, Zheng L, Wang YM, Pokorna H, Bauer PC, Costabel U. Soluble CD14 is increased in bronchoalveolar lavage of active sarcoidosis and correlates with alveolar macrophage membrane-bound CD14. Am J Respir Crit Care Med 1995; 151: 544-547.

16. Dubin W, Martin TR, Swoveland P, et al. Asthma and endotoxin: lipopolysaccharide-binding protein and soluble CD14 in bronchoalveolar compartment. Am J Physiol 1996; 270: L736-L744.

17. Hasday JD, Dubin W, Mongovin S, et al. Bronchoalveolar macrophage CD14 expression: shift between membrane-associated and soluble pools. Am J Physiol 1997; 272: L925-L933.

18. Ward C, Fenwick J, Booth $\mathrm{H}$, Walters EHW. Albumin is not suitable as a marker of bronchoalveolar lavage dilution in interstitial lung disease. Eur Respir J 1997; 10: 2029-2033.
19. Esmore DS, Brown R, Buckland M, et al. Techniques and results in bilateral sequential single lung transplantation. J Cardiac Surg 1994; 9: 1-14.

20. Yousem SA, Berry GJ, Cagle PT, et al. Revision of the 1990 working formulation for the classification of pulmonary allograft rejection. $J$ Heart Transplant 1996; 15: 1-15.

21. Hoogensteden HC, van Hal PT, Wijkhuijs JM, Hop W, Hilvering C. Differences in expression of monocyte/macrophage surface antigens in peripheral blood and bronchoalveolar lavage cells in interstitial lung diseases. Lung 1993; 171: 149-160.

22. Pforte A, Schiessler A, Gais P, et al. Expression of CD14 correlates with lung function impairment in pulmonary sarcoidosis. Chest 1994; 105: 349-354.

23. Leturq DJ, Moriarty AM, Talbott G, Winn RK, Martin TR, Ulevitch EJ. Antibodies against CD14 protects primates from endotoxin-induced shock. J Clin Invest 1996; 98: 1533-1538.

24. Ward C, Whitford H, Snell GI, et al. Bronchoalveolar lavage macrophage and lymphocyte phenotypes in lung transplant recipients. J Heart Lung Transplant 2001; 20: 1-11.

25. Ward C, Effros RM, Walters EH. Assessment of epithelial lining fluid dilution during bronchoalveolar lavage. In: Haslam PL, Baughman RP, eds. Report of the European Respiratory Society Task Force: Guidelines for Measurement of Acellular Components and Recommendations for Standardisation of Bronchoalveolar Lavage (BAL). Eur Respir Rev 1999; 9: 66, pp. 32-37.

26. Parsons PE, Gillespie MMK, Moore EE, Moore FA, Worthen GS. Neutrophil response to endotoxin in adult respiratory distress syndrome: role of CD14. Am J Respir Cell Biol 1995; 13: 152-160.

27. Worthen GS, Haslett C, Rees ASJ, Gumby RS, Henson JE, Henson PM. Neutrophil-mediated pulmonary vascular injury: synergistic effects of trace amounts of lipopolysaccharide and neutrophil stimuli on vascular permeability and neutrophil sequestration within the lung. Am Rev Respir Dis 1987; 136: 19-28.

28. Kruger C, Schutt C, Obertacke U, et al. Serum CD14 levels in polytraumatized and severely burned patients. Clin Exp Immunol 1991; 85: 297-301.

29. Hoheisel G, Zheng L, Teschler H, Striz I, Costabel U. Increased soluble CD14 levels in BAL fluid in pulmonary tuberculosis. Chest 1995; 108: 1614-1616. 